\title{
TRABALHO IMATERIAL E COOPERAÇÃO PRODUTIVA: Considerações sobre a produção em design a partir das redes de criação colaborativa
}

\author{
Mariana Faro Ferreira \\ Universidade Federal do Rio de Janeiro \\ mari.ffaro@gmail.com
}

Resumo: Diante da emergência de diversas práticas associadas à produção colaborativa e cooperativa no âmbito da criação e da inovação, pretendemos indagar o estatuto dos discursos e práticas ligados a cooperação na produção em design. Para isso, partimos de um estudo sobre as transformações do trabalho nas últimas décadas para problematizar as relações de produção contemporâneas, fortemente assentadas sobre as dinâmicas de cooperação social. Em nossa abordagem, consideramos as distintas qualidades do trabalho no pós-fordismo e as novas dinâmicas produtivas que se desenvolvem para além dos tradicionais espaços de produção, através de densas redes sociotécnicas e novos dispositivos de controle (DELEUZE, 2008). Essas redes são os canais principais que possibilitam na última década do século $\mathrm{XX}$, particularmente com a popularização da internet através da web, certa explosão participativa (ANTOUN, 2008), em parte responsável por uma reconfiguração dos modelos de produção e comunicação massiva. Nos espaços produtivos que se delineiam a partir dessas redes, a produção de valor está fortemente ligada às dimensões subjetivas e comunicacionais diretamente implicadas nas relações sociais a partir das quais essas redes se estruturam. É nesse contexto que a produção em design passa a envolver cada vez mais as práticas cooperativas como terreno de desenvolvimento e inovação. Em uma redefinição das categoriais de valor e trabalho, onde o capitalismo contemporâneo aparece em sua dimensão cognitiva e social, buscamos situar a atividade de design entre aquelas funções características de um trabalho de tipo imaterial, essencialmente pautado em dimensões sociais e comunicativas (NEGRI, LAZZARATO, 2013). A capacidade de estabelecer redes, de criar canais de comunicação e, de maneira geral, todo o capital humano (GORZ, 2005) de projetistas e comunicadores são repetidamente convocados por um mercado de trabalho que opera sobremaneira sob o signo da comunicação e da mobilização da subjetividade. Tomando os ofícios estético-comunicacionais, levantamos algumas questões acerca das consequências desses novos imperativos do trabalho contemporâneo para o campo do design. Partindo das redes sociais na internet como campo privilegiado de desenvolvimento de relações de trabalho livre (TERRANOVA, 2000) que envolvem um imperativo de colaboração e de criatividade, nossa análise estará centrada nas práticas presentes em plataformas de criação 
colaborativa, em especial nas redes brasileiras itsNoon e Mineo. Mecanismos de participação, níveis de autonomia e estratégias de recompensa e remuneração são alguns dos tópicos que abordamos para elaborar questionamentos sobre esses modelos de trabalho criativo. Conclui-se que a análise desses espaços de trabalho nos permite identificar diferentes formas de cooptação daquilo que se produz nas redes de criação, mas também o desenvolvimento de diferentes táticas de apropriação pelos participantes nas plataformas de criação. Esses diferentes usos, apesar de continuamente convocados pelos gestores das plataformas, indicam uma produção que excede os comandos e normatizações iniciais. As relações que emergem da participação nas plataformas analisadas apontam para a criação, em certa medida, de diferentes redes e valores pelos seus usuários. Por fim, a partir das questões e apontamentos inicialmente levantados, procuramos tecer algumas reflexões sobre o horizonte, entre controles e resistências possíveis, desse tipo de produção no campo do design.

Palavras-chave: design, trabalho, colaboração, redes sociais, itsnoon

\section{INTRODUÇÃO}

Co-criação, inovação aberta e "arquitetura de participação" são alguns dos termos recorrentes em uma série de iniciativas que associam os processos de produção à intensificação de suas dimensões sociais. Apesar de não se caracterizarem como novidade absoluta nas práticas produtivas, os discursos sobre colaboração parecem despontar com maior intensidade nas literaturas empresariais dos últimos vinte anos. De um lado os consumidores são cada vez mais convidados à colaboração em projetos abertos, enquanto para as empresas esse tipo de desenvolvimento colaborativo aparece como solução estratégica para uma efetiva contribuição do usuário em seus processos de concepção. Com essas reconfigurações nos modos de produzir, aos profissionais de criação e desenvolvimento lança-se o desafio contínuo de serem capazes de produzir de forma aberta, englobando nos processos de desenvolvimento não apenas seus pares como também os usuários finais de seus produtos. Do ponto de vista de designers, publicitários e outros profissionais implicados nas chamadas "indústrias criativas", a capacidade de estabelecer redes e produzir a partir delas tornase uma ferramenta constantemente requerida. Ao analisarmos algumas das iniciativas voltadas para a criação colaborativa nas redes tecnológicas e sociais, observamos certo imperativo de participação e criatividade que valora aqueles dispostos a contribuir com tempo e ideias em projetos coletivos. A possibilidade de contribuir com 0 desenvolvimento de um projeto e os benefícios pessoais advindos desse tipo de ação se apresentam como alguns dos atrativos de um sedutor convite à colaboração, mas não são os únicos. A fim de pensarmos como a colaboração emerge como prática fundamental nos processos produtivos contemporâneos, recorremos a alguns discursos que sinalizam para a construção desse e de outros imperativos característicos das reconfigurações do trabalho a partir da década de 1990. Publicações como o livro Makers (2012), do norte-americano Chris Anderson, apresentam uma revolução em curso, pautada pelo modelo de criação aberta e pelas novas possibilidades de desenvolvimento e produção trazidas pelas redes tecnológicas de comunicação distribuída. Com efeito, diversas práticas de criação a partir das redes de comunicação surgem como celebradas soluções para problemas de distribuição enfrentados outrora. 
Entretanto, consideramos que essas práticas colocam novas questões a confrontar, em especial no que concerne aos modelos de trabalho que se delineiam em tempos de produção pós-fordista. Quando a esfera da reprodução (circulação, consumo, relações sociais) se torna imediatamente produtiva, a produção que se desenvolve a partir de nossas redes sociais torna-se a principal fonte contemporânea de valor. Essas práticas, argumentamos, emergem inseridas em um novo processo de acumulação, em cuja base situa-se o "trabalho vivo", que implica, sobretudo, habilidades ligadas ao conhecimento, às relações sociais e à comunicação. Cabe a esta reflexão incipiente indagar os modos de funcionamento de algumas plataformas de produção colaborativa, a fim de darmos alguns passos em direção à necessária complexificação das análises sobre esse tipo de prática no campo do design.

Como parte de uma pesquisa em andamento, assinalamos como objetivo deste trabalho em específico, pontuar as formas de funcionamento de duas plataformas de produção colaborativa. Tal levantamento considera como elementos de análise os mecanismos de participação, os modos de criação e as condições de remuneração possibilitadas nas duas plataformas. Pretendemos com esses objetivos compreender a complexidade dessas novas práticas produtivas a partir dos usos específicos que cada uma destas plataformas apresenta. Em cada uma delas, coube assinalar tanto as estratégias empregadas por seus idealizadores quanto os possíveis usos particulares, que os participantes desenvolvem. Ao identificarmos as normatizações e convocações de que essas redes lançam mão, queremos em paralelo lançar luz sobre as diferentes apropriações que se desenvolvem em seu interior. Dedicamos as etapas posteriores deste trabalho para a descrição desses modelos de uso e os deslocamentos que eles podem provocar, visando considerar os horizontes possíveis de atuação a partir dessas redes.

Essa investigação considera em seu desenvolvimento os estudos empreendidos nas últimas duas décadas sobre as transformações do capitalismo contemporâneo e o paradigma do trabalho imaterial. Tal paradigma compreende a hegemonia de um trabalho que se desenvolve através das redes de comunicação e que implica acima de tudo a produção de formas de vida (NEGRI, LAZZARATO, 2013). Nessa linha, trabalhar hoje significa criar valor, estabelecer relações e, especialmente, produzir-se continuamente enquanto sujeito empregável (GORZ, 2005). O trabalho contemporâneo, em suas mais diversas possibilidades de atuação, é comunicativo e afetivo e se estabelece não mais no chão de fábrica, pautado pela relação salarial, mas tem por lugar ambientes flexíveis de produção e esquemas precarizados de remuneração. As modulações pelas quais operam os novos dispositivos de controle do tempo de trabalho (DELEUZE, 2008) tornam nossas relações mais flexíveis, entretanto, sem eliminar as contínuas explorações da força produtiva. Na sobreposição do trabalho vivo (aquele em que o conhecimento e a comunicação são empregados na produção) sobre o trabalho mecânico e automatizado, se recompõe em novos níveis a exploração de corpo/mente dos trabalhadores, envolvendo a totalidade da vida na produção de valor. De forma geral, trabalhamos formandos redes e formando redes trabalhamos. São, nessa perspectiva, as nossas redes e relações sociais as principais fontes de produção capitalizáveis.

Dada a dimensão de rede dos novos espaços produtivos sobre os quais nos detemos, lançamos mão de uma investigação de tendência cartográfica como método condutor de nossa aproximação com os objetos investigados. Nesse sentido, cartografar implica certa desconstrução prévia dos referenciais teóricos, que devem ser construídos 
no próprio contato com os contextos experimentados na investigação. (PASSOS; BARROS; DA ESCÓCIA, 2009) Buscamos a referência à cartografia como método orientador da investigação por compreender a pertinência da adequação da prática cartográfica aos ambientes sociais que se desenvolvem na cibercultura, ao considerar os objetos em sua dimensão relacional, dinâmica e subjetiva. A partir daí será realizada uma análise do ambiente social que se estabelece nas redes ItsNoon e Mineo. Trata-se de um esforço em abandonar certos pressupostos rígidos diante dos objetos investigados e indagar os próprios discursos que se estabelecem na plataforma. Para compreender as práticas que se apresentam nas plataformas analisadas, consideramos necessário abandonar, a principio, as visões deterministas dos tipos de relação produtiva que acontecem nesses ambientes, para possibilitar uma análise mais ampla dos desvios e movimentos que ali se estabelecem.

\section{CAPITALISMO COGNITIVO E AS TRANSFORMAÇÕES DO TRABALHO CONTEMPORÂNEO}

Mobilizamos em nossa articulação conceitual uma série de autores que se debruçam sobre as transformações nos modos de produção e das consequentes reconfigurações na produção, nos modos de expropriação e das novas resistências que elas ensejam. Ao assinalar a configuração de um capitalismo de tipo cognitivo, cultural e linguístico, essas pesquisas indicam uma tendência que aponta para a centralidade da informação, das redes e habilidades comunicativas na produção de valor. Nesse novo paradigma, a expropriação da produção passa a se dar através das redes e a partir do que elas criam e desenvolvem, não se restringindo mais ao espaço delimitado da fábrica como ocorria no trabalho industrial de tipo fordista. Antônio Negri e Maurizio Lazzarato, em Trabalho imaterial e produção de subjetividade (2013) contribuem para a formação desse campo teórico, apontando para a constituição das "formas de vida (nas suas expressões coletivas e cooperativas) como fonte de inovação" e valor (NEGRI; LAZZARATO, 2013. p. 72). As redes, fábricas sociais do capitalismo cognitivo, passam a ser o espaço da produção de subjetividades. Assumimos a afirmação do paradigma do trabalho imaterial, cuja base situa-se nos trabalhos de Negri e Lazzarato originalmente publicados no início dos anos 1990, por tratar-se de um esforço teórico que opera uma revisão no pensamento marxista ortodoxo, repensando a noção de classe e trabalho na passagem ao pós-fordismo. Esta atualização das categoriais e do pensamento sobre o trabalho contemporâneo nos parece útil para abordar relações novas na produção que pouco se assemelham com o modelo industrial e disciplinar que vigora até os anos 1960 e 1970. Diante da passagem ao paradigma do trabalho imaterial, trabalho que mobiliza a vida (Negri \& Lazzarato, 2013), a produção não está mais restrita ao espaço e ao tempo das fábricas e agora se confunde com toda a esfera da reprodução social. A produção nos ofícios estético comunicacionais se desenvolve a partir de uma relação bem específica com a esfera do consumo, incluindo sistematicamente a reprodução social nos tempos e espaços destinados à produção. Por isso a tendência de transformação dos ambientes de trabalho, como as agências de comunicação e escritórios de inovação, em verdadeiros espaços de lazer e consumo. É nessa esfera das relações sociais, incluída na produção de valor, que se apresenta a principal matéria prima do trabalho imaterial. Nesse modelo, a subjetividade do trabalhador das indústrias criativas, suas experiências e redes pessoais não só podem, como devem ser implicadas em seus processos de trabalho. $O$ trabalho imaterial é a interface dessa nova relação entre produção e consumo, ativando-a e organizando continuamente. A 
característica fundamental desses novos processos produtivos no campo do design é que eles marcadamente se alimentam de subjetividade e produzem subjetividade. Nessa interface, os designers hoje, em especial, atuam como agentes intermediários conferindo materialidade aos desejos e imaginários e, por outro lado, investindo novos desejos a partir dos produtos que desenvolvem. Não se trata de produtos a serem consumidos, mas da criação de mundos de desejo a partir da circulação de produtos. Produção simbólica de mundos em que os próprios trabalhadores imateriais estão implicados e que se torna o campo de realização das funções comunicativas daquilo que criam. Nesse duplo mecanismo em que operam os criadores e suas redes, o pósfordismo se apresenta tanto na (a) ativação da cooperação produtiva quanto na (b) produção dos conteúdos culturais da mercadoria. (LAZZARATO, NEGRI, 2013). A dimensão social sobre a qual se organiza esse trabalho funciona "através de redes linguísticas, coorporativas, eletrônicas e digitais, todas extremamente materiais, e tem lugar através de tipos de associação - e movimentos - que são multitudinários." (NEGRI, 2012, p. 118) Móvel, flexível e corpórea, essa força de trabalho não se apresenta individualmente mas sim a partir de um conjunto de corpos.

O trabalho imaterial se constitui em formas imediatamente coletivas e não existe, por assim dizer, senão sob a forma de rede e fluxo. A submissão à lógica capitalista da forma de cooperação e do "valor de uso" desta atividade não tolhe a autonomia e a independência da sua constituição e do seu sentido. Ao contrário, ela abre antagonismos e contradições. (NEGRI; LAZARATTO, 2013, p. 50)

Nesse movimento, os autores apontam para a necessidade de se "superar a noção de criatividade como expressão de "individualidade" ou como patrimônio das "classes superiores" (NEGRI; LAZARATTO, 2013, p. 52). A criação não está mais circunscrita a setores produtivos específicos, mas se constitui como o campo principal onde o valor é determinado dentro do capitalismo cognitivo.

\subsection{O PARADIGMA PÓS-INDUSTRIAL E AS REDES DE PRODUÇÃO COLABORATIVA}

Nas transformações do sistema de acumulação capitalista vigente, novas formas de expropriação se constituem. Como abordamos, as relações de trabalho não cessam de se reconfigurar arrastando com elas o imperativo de novas subjetividades trabalhadoras. A flexibilização do trabalho, em uma economia orientada a relações de serviço, traduz a face não localizada e desestabilizada da produção no pós-fordismo. Os modos de produção baseiam-se, sobretudo, nas forças inventivas da criatividade e na comunicação. Onde não mais se estabelece a nítida separação do tempo e dos espaços de produção e de reprodução social, como podemos identificar nas práticas de home office e de todo trabalho nas redes digitais (DELEUZE, 2008). Passamos do emprego à empregabilidade, através da contínua necessidade de nos mantermos empregáveis, investindo no desenvolvimento pessoal constantemente (troca de funções, circulação nas redes, busca ininterrupta por qualificação e experiências que se traduzem em acúmulo de "capital humano"). Nesse sentido, a noção de rede tem marcado os discursos contemporâneos sobre a produção enquanto os modelos da inovação e da criatividade se encontram ainda mais implicadas nesses novos movimentos. Diversos aplicativos, sites, plataformas e comunidades na internet despontam tendo como mote o desenvolvimento de projetos a partir da cooperação possibilitada pelo encontro de diferentes sujeitos em espaços online. Esses espaços se valem, sobretudo, da web como 
terreno catalisador do desenvolvimento de projetos colaborativos e incluem iniciativas das mais diversas naturezas, como plataformas de financiamento coletivo ou aquelas destinadas ao desenvolvimento e à viabilização de projetos, como as plataformas Minio $^{1}$ e Ponoko ${ }^{2}$. No âmbito dos ofícios ligados à criatividade e à produção de imagens gráficas (como o design e a publicidade) é possível encontrar também diversas iniciativas que se propõem a promover a produção colaborativa de projetos através de seus ambientes virtuais. Essa produção, que acontece cada vez mais fora dos tradicionais ambientes produtivos, sejam aqueles fabris ou empresariais, coloca novas questões sobre as relações de trabalho, acumulação e expropriação de valor na rede. Diante de um sistema de acumulação que produz novas formas de exploração baseadas nas forças inventivas, da criatividade e da expressão, partimos das práticas de trabalho criativo que se estabelecem no ciberespaço para formular nossas questões.

Nos mais diferentes campos, diversas reflexões foram feitas sobre os impactos das tecnologias digitais nos planos econômico e social. Uma grande lista de neologismos e frases de efeito surgem e se disseminam, tais como 'a nova economia', 'a economia digital', 'wikinomics', 'crowdsourcing', 'inteligência coletiva, 'a cauda longa', 'a sabedoria das multidões', entre outros. (HESMONDHALGH, 2010). Sem dúvida, as tecnologias de comunicação e informação (TiCs), a web, e os meios digitais de compartilhamento são parte de um adensamento das relações comunicacionais de caráter participativo e distribuído. Uma proliferação de redes sociotécnicas que abrem possibilidades, mas que requerem ressalvas sobre as imbricações entre o plano econômico e o social. Além das apressadas simplificações das relações entre cooperação produtiva e a comunidade explorada, faz-se necessário considerar as questões materiais que perpassam a emergência dessas práticas de produção a partir das redes e seus desdobramentos. Trata-se de por em perspectiva as condições de emergência desse tipo de trabalho que se desenvolve a partir das redes tecnológicas de comunicação, fugindo tanto de concepções tecnofóbicas quanto daquelas de caráter apologético. Uma vez que é essa "socialização/intensificação dos níveis de cooperação dos saberes, das subjetividades dos trabalhadores, dos dispositivos tecnológicos e organizativos que redeterminam completamente os termos da questão [do trabalho autônomo]." (NEGRI; LAZZARATO, p. $108,2013)$. Diante dessas novas qualidades e requisitos do trabalho cognitivo, as redes digitais se colocam como novos meios primordiais de produção, onde a informatização da indústria transforma o trabalho em "gestão de um fluxo contínuo de informações" (GORZ, 2003, p. 17).

O que é produzido a partir da cooperação social nessas redes torna-se imediatamente coletivo e excede as antigas definições de valor e de tempo de trabalho necessário. Por outro lado, essa indefinição vem acompanhada não de uma redução mas de aumento nas jornadas de trabalho que se estendem pós horário rígidos e investem os mais diversos ambientes (de lazer, de consumo, de relações pessoais). Para as empresas que se valem dessas relações e dessa extensão dos espaços produtivos, a cooperação social se apresenta como fonte inesgotável de valor, por baixos custos. A possibilidade de centenas de pessoas qualificadas contribuindo gratuitamente motivadas por um desejo de participação, entre outros benefícios ligados à

\footnotetext{
${ }^{1}$ Plataforma brasileira de desenvolvimento colaborativo de produtos sustentáveis. Acesso à plataforma em http://www.mineo.co/.

2 Plataforma online neozelandesa dedicada ao compartilhamento, fabricação e comercialização de projetos de produto. Acesso à plataforma em http://www.ponoko.com/.
} 
centralização do valor produzido pelas redes de cooperação, aparece não apenas nas publicações destinadas ao gerenciamento e à administração mas também naquelas especificamente focadas nas práticas de design.

\section{O DESIGN E A COOPERAÇÃO SOCIAL}

Em Participate - Designing with user-generated content, Helen Armstrong e Zvezdana Stojmirovic (2011), professoras da Miami University e do Maryland Institute College of Art, respectivamente, traçam um perfil das habilidades requeridas aos designers diante das transformações paradigmáticas que marcam os processos de produção e distribuição contemporâneos. Com o subtítulo "O guia do designer para a co-criação", o texto de Armstrong e Stojmirovic pretende funcionar como um manual para que designers, projetistas e artistas em geral apreendam as técnicas e métodos necessários para o desenvolvimento orientado à participação dos usuários, valendo-se dos conteúdos criados voluntariamente por estes para criação de seus projetos. A concepção das autoras norte-americanas não se encontra isolada. Com efeito, seu discurso é tributário de uma tendência que apresenta como indissociáveis a produção de valor nas práticas de criação e as dinâmicas próprias das redes sociais. Tais iniciativas aparecem associadas a um imperativo de cooperação e produção que tem por base as redes sociais mediadas a partir da internet. Nessas relações, divisamos um reflexo das novas formas de produção de valor no capitalismo cognitivo, onde a expropriação $a$ posteriori ocorre na captura daquilo que é produzido nas redes de cooperação. $\mathrm{Na}$ atividade de design, onde o trabalho imaterial se desenvolve em sua vertente de trabalho interativo - resolução de problemas e de produção simbólica (SZANIECKI, 2012), podemos identificar na produção de espaços e mecanismos de colaboração uma estratégia produtiva, para envolver diferentes afetos e subjetividades em projetos centralizados. Dessa forma, as soluções (imagens, conceitos, projetos) e, de maneira geral, todas as relações sociais produzidas na atividade projetual do design, se encontram mais do que nunca possibilitadas por essa organização das expressões coletivas e sociais. A partir desses apontamentos, questionamos: as plataformas de colaboração ligadas à área do design podem, efetivamente, funcionar como ambientes de criação distribuída ou se constituem como meios de centralizar (e controlar) a capacidade de criação e invenção das redes?

\subsection{PLATAFORMAS DE CRIAÇÃO EM DESIGN}

Após a introdução de algumas questões teóricas que subsidiam esta reflexão, analisamos os modelos de funcionamento de duas redes: as plataformas brasileiras Mineo e ItsNoon. Para compreendermos em que medida seus discursos se relacionam com as práticas do trabalho criativo nas redes, pretendemos apresentar 0 funcionamento e as dinâmicas de colaboração propostas pelas duas plataformas.

\subsubsection{ITSNOON}

Entre as definições presentes no site da plataforma brasileira de produção criativa itsNoon está aquela que a apresenta como um "marketplace de economia criativa". Criada em 2009 e em operação desde então, a plataforma reúne múltiplos agentes (entre participantes, gestores e patrocinadores) com ações diversas na sua dinâmica de funcionamento. Em sua página de apresentação, a rede convida os visitantes a participarem de chamadas criativas, mediante a criação de perfis - que funcionam como uma página pessoal dentro do site - onde podem ser postadas as 
criações de cada participante e a partir da qual são possibilitadas interações com outros usuários. Segundo o próprio texto, as chamadas são convites feitos para que os usuários respondam a questões de jeitos criativos. Estas respostas podem ser concebidas em formatos diversos, de cartazes a fotografias e vídeos. O espaço estimula ainda a interação entre os usuários, chamando os participantes a co-criar, encontrar parceiros de trabalho, além de votar nas criações. O site possibilita a remuneração pelos trabalhos realizados, uma vez que, de acordo com a página, todas as chamadas criativas remuneram os melhores criadores. As questões que dão origem às chamadas criativas são propostas por agentes diversos, de empresas a organizações não governamentais, interessados em obter acesso a percepções e ideias de pessoas de diversas partes do país. Cabe atenção especial à forma como o serviço é apresentado às instituições, "um espaço para acessar pessoas de todo os estados do Brasil (...) e fomentar o trabalho em rede, comprando informação e conteúdo criativo. Um material abundante, fruto da reflexão, interação e co-criação entre os usuários". " A participação na rede e as possibilidades de interação proporcionadas por ela se apresentam como benefício tanto para aqueles usuários dispostos a produzir peças voluntariamente quanto para os agentes interessados em acessar tais produtos. Compreende-se que diversos interesses estão presentes nestas dinâmicas, entretanto, a participação e os conteúdos produzidos de forma colaborativa parecem ser o mote que agrega os diferentes agentes que se comunicam através da rede.

Com relação às formas de participação, quatro modos possíveis de ação na rede são apresentados na homepage. Assim, qualquer pessoa ou organização, mediante a criação de um perfil na plataforma, poderá a) participar das chamadas criativas; b) abrir sua própria chamada criativa; c) criar comunidades criativas; d) realizar apoios criativos. Analisando as chamadas criativas em curso na plataforma (registramos 281 chamadas encerradas e 3 chamadas criativas abertas), porém com maior ênfase nos modos de funcionamento propostos por sua gerência, discutiremos alguns pontos observados que estabelecem relações com as questões ligadas ao trabalho criativo nas redes sociais.

A princípio, qualquer usuário da rede pode abrir sua própria chamada, desde que seja pago o valor mínimo de $\mathrm{R} \$ 100$, indicado como referente ao uso da plataforma. As chamadas funcionam com premiações, remunerações (financeiras ou não) ofertadas àqueles usuários dispostos a responder às questões propostas em cada uma delas. $\mathrm{A}$ premiação de cada chamada deve ser escolhida pelo seu proponente, não estando aí delimitada nenhuma condição para sua constituição. É possível oferecer remunerações em dinheiro, outros prêmios (exposições, créditos, participação em publicações), bem como a combinação de ambas as formas. Os valores em dinheiro ofertados, contudo, devem obedecer à fórmula valor distribuído $+20 \%$ em taxas administrativas, percentual destinado aos custos operacionais da plataforma. Os pagamentos, realizados apenas àqueles que tiverem suas propostas selecionadas, devem ser feitos através de créditos em contas dentro da ItsNoon. Presume-se daí que aqueles que não forem escolhidos terão ofertado seu trabalho sem remuneração. Contudo, uma ressalva orienta os proponentes "Lembre-se: toda ideia/criação tem seu valor. Quanto maior o prêmio, maior a chance das pessoas participarem das \#chamadas.". Além das chamadas, há ainda a possibilidade de remuneração dos próprios usuários da plataforma (que

\footnotetext{
3 Trecho retirado da página de apresentação da rede ItsNoon. Disponível em <http://itsnoon.net/> Acesso em 15 de outubro de 2012.
} 
qualificam e conferem pontos para as peças que mais gostarem) e o financiamento coletivo (arrecadação de fundos nos modelos de crowdfunding. ${ }^{4}$

Abordamos também na análise os termos referentes aos direitos autorais e de uso das peças e obras criadas. De acordo com a proposta da plataforma, existem duas formas de licenciamento possíveis. Uma ligada ao direito de uso de conteúdo e informação, para quem deseja obter insights e informações com as ideias postadas na chamada. O segundo tipo de licenciamento, que compreende a compra de conteúdo e informação, destina-se aqueles proponentes que desejam comprar ideias através da chamada criativa. Sob essa licença todos os usuários que aceitarem participar cedem automaticamente os direitos de uso de suas criações para o autor da chamada. Além das peças e criações produzidas a partir das convocatórias, é oferecido pela gerência da plataforma também a possibilidade de extrair relatórios contendo os dados de participação referente à sua chamada (como quantidade de pessoas participantes, quantidade de ideias inscritas, formato das ideias inscritas, localização geográfica dos participantes, seu gênero e idade). A equipe se dispõe ainda a fornecer outros tipos de relatório a partir do interesse e da solicitação daqueles proponentes.

Como as primeiras análises sobre este objeto indicavam, percebe-se em todo o discurso produzido pelos mediadores da rede certa valorização das ações colaborativas. Após a criação de seus perfis os usuários da rede são convocados a "ativar e mobilizar" suas próprias redes, uma vez que "quanto mais gente, mais conteúdo, diversidade e colaboração". A possibilidade de comentar, dar feedbacks e interagir com os participantes das chamadas também é promovida em todas as áreas da plataforma. Tal ambiente evidencia constantemente a insuficiência do ato individual de criar. 0 trabalho em rede torna-se imperativo a partir dessas estruturas uma vez que a partir delas é possível estar em contato e em troca contínua com outros sujeitos igualmente convocados a colaborarem a partir de projetos e briefing coletivos. A plataforma aqui se anuncia como o grande espaço onde se congregam diversos criadores com a mesma disposição em co-criar. Apesar de ser uma característica proclamada como diferencial desta rede, tais modos de produção passam a ser o modo de funcionamento fundamental de todas as atividades produtivas realizadas através das redes sociais online. Expressar sentimentos, sensações e desejos. Participar a partir da colaboração, comunicação e co-criação. Tais expressões perpassam constantemente as chamadas e convocatórias da rede analisada. São as possibilidade de interação, de estabelecer contatos e expressar criativamente suas percepções que definem os principais atrativos por ela veiculados. Não basta conhecimento técnico, quando cada vez mais aspectos subjetivos e o investimento das capacidades afetivas parecem condição fundamental para a participação e legitimação em uma nova lógica produtiva.

\subsubsection{MINEO}

"Uma plataforma online de criação colaborativa de produtos sustentáveis." Em sua homepage a plataforma brasileira Mineo, fundada em 2012, explicita em apenas quatro simples passos seu modelo de funcionamento, são eles: 1) ideias; 2) validação; 3) prototipação e 4) finalização. Funcionando nos moldes de uma startup a plataforma torna possível que uma ideia de produto seja apresentada por um usuário e, a partir das

\footnotetext{
${ }^{4}$ O financiamento coletivo (crowdfunding) se caracteriza pela arrecadação de capital para iniciativas de interesse coletivo por meio da combinação de múltiplas fontes de financiamento, principalmente de pessoas físicas interessadas na iniciativa.
} 
interações possibilitadas pela exposição na plataforma, que essa ideia receba opiniões dos colaboradores interessados no seu desenvolvimento. A comunidade atuante na plataforma é responsável coletivamente pelo aprimoramento da ideia lançada originalmente. Nas etapas finais, o produto passa por uma etapa de validação que tem por objetivo a viabilização de sua produção. O ciclo de desenvolvimento se encerra com a distribuição do produto em lojas parceiras.

De maneira mais específica, ao abordarmos os mecanismos de funcionamento propostos e os discursos das chamadas de participação, identificamos alguns dos objetivos ligados à concepção de produtos. A rede pretende funcionar como uma comunidade que pense em produtos que solucionem problemas reais, tendo como desafio auxiliar empresas e grupos brasileiros que pesquisam e desenvolvem materiais de forma responsável a diversificarem seus materiais por meio de novas aplicações. Assim, em um primeiro momento de participação na rede, cabe àqueles que pretendem inscrever ideias consultar os materiais propostos nas chamadas criativas. Da mesma maneira que a rede itsNoon, o Mineo também funciona a partir de chamadas criativas. Porém suas chamadas buscam convocar para o desenvolvimento a partir de materiais a serem empregados nos projetos apresentados e não de temáticas predeterminadas como ocorre na itsNoon. Na apresentação de seu modelo de funcionamento, a plataforma anuncia o desejo de se transformar em uma "comunidade de desenvolvimento". Para tanto, considera necessária a participação de "pessoas engajadas". Percebemos aqui o valor conferido ao comprometimento com os processos de desenvolvimento das ideias. Não se trata apenas de participar, mas de permanecer cultivando relações na rede, contribuindo com ideias e insights sobre o produto em desenvolvimento. Para inscrever uma ideia de produto na plataforma o usuário paga uma taxa de $\mathrm{R} \$ 10,00$ (dez reais), que deve funcionar como estimulo a uma curadoria prévia pelos proponentes, evitando uma profusão no envio de ideias que não receberiam o acompanhamento esperado dos autores caso a submissão fosse gratuita. Esse cuidado se justifica pela dinâmica de funcionamento da plataforma onde se torna fundamental tanto a participação contínua do proponente da ideia como da sua rede de amigos. A plataforma estimula a divulgação dos projetos propostos nos canais pessoais do inventor e a interação com os demais usuários que fizerem comentários sobre o produto. Além da interação na página da ideia proposta, a plataforma também convida os proponentes a participarem dos outros projetos, interagindo com seus autores. $\mathrm{Na}$ dinâmica de funcionamento da rede Mineo, é frequentemente ressaltada a importância dos colaboradores para o sucesso dos projetos. O realizador de uma ideia deve contar com os comentários para que, a partir do "jogo da colaboração", seu projeto se desenvolva. A mediação da rede ainda ressalta que o tempo dos colaboradores pode "representar uma grande ajuda para o realizador de uma ideia". Dessa forma, a rede aposta nas contribuições da própria comunidade para valorar uma colaboração. As ideias e contribuições recebem aplausos da comunidade (uma espécie de métrica de aprovação), o que confere maior ou menor influência sobre o produto final. Essa influência se converte, posteriormente, em benefícios financeiros provenientes da venda do produto. "Quanto mais colaborações uma ideia tiver, melhor a chance de ela se tornar um bom produto, e mais pessoas irão ganhar com a venda final." Há ainda a possibilidade de escolher a forma como deseja opinar, seja com comentários, votos ou mesmo imagens.

Cabe à mediação o acompanhamento da ideia de produto e a distribuição da remuneração financeira proveniente de sua venda, caso ele seja escolhido pelo Mineo 
para ser produzido. A seleção das ideias envolve a combinação de diferentes critérios que inclui os "aplausos da comunidade, o nível de engajamento envolvido na criação da ideia, além de aspectos técnicos e econômicos, que justifiquem a fabricação da ideia" 5 . Após a seleção, a equipe do Mineo (composta por designers e engenheiros com experiência em co-fabricar produtos em rede) gerencia com fornecedores os materiais e estruturas necessários para a modelagem, prototipagem e fabricação do produto. Há uma fase prévia de testes de aceitação na qual é vendido um lote inicial. A comunidade é chamada a financiar esse lote junto com a gerência do Mineo. Aqueles que investem nos lotes iniciais recebem em contrapartida o próprio produto, caso seja atingida a meta financeira estipulada. Caso contrário, o dinheiro é devolvido para os investidores e o produto não é fabricado. A justificativa envolve os critérios de aceitação, "afinal, pra que colocar no mundo um produto que não faz sentido pra ninguém?". Se o lote inicial for vendido o produto passa à linha de produtos da rede, sendo vendido na loja online. Sobre a distribuição dos lucros provenientes da venda, a rede define a possibilidade de remuneração de todos aqueles que estiverem envolvidos na construção da ideia de um produto produzido. Assim, tanto o autor da proposta inicial quando os colaboradores são remunerados financeiramente. Dois modos iniciais de remuneração são apresentados. (a) produtos vendidos no varejo têm $15 \%$ do preço final do produto revertido para a comunidade Mineo (sendo, $45 \%$ para o autor da ideia e $55 \%$ divididos entre os colaboradores, em função do número de aplausos que suas colaborações receberam ao longo da criação do produto); b) produtos vendidos no atacado têm $5 \%$ do preço final revertidos para a comunidade Mineo (sendo aqui aplicada mesma forma de divisão do varejo: $45 \%$ para o autor e $55 \%$ para os colaboradores).

Conclui-se que essa produção criativa, no contexto das redes online, se estrutura em outras dimensões diferentes das estabelecidas em contextos produtivos modernos. Com o valor de inovação se sobrepondo ao valor de uma autoria individual, como observado nas relações colaborativas de criação nas plataformas ItsNoon e Mineo. Como podemos observar, trata-se nos dois espaços, ainda que de diferentes formas, de ideias em formação abertas a transformação contínua a partir de um processo de cocriação, de relação com os conteúdos produzidos na rede. Percebe-se nessa demanda por espaços de expressão e de conexão produtiva que saberes e habilidades são transformados em capital com o qual esse trabalhador informal (se) negocia na lógica empresarial, se estabelecendo como um indivíduo-empresa. Como aponta André Gorz (2005), essa mobilização ininterrupta dos predicados vitais pode ser claramente percebida nos serviços relacionais, mas também nos ofícios de caráter artístico, como a moda, a publicidade e, abordado aqui, o design. De maneira geral, os ofícios ligados à criatividade e à inovação parecem encontrar na rede o espaço ideal para o desenvolvimento continuo e compartilhado de ideias, insights e novos projetos. A desmaterialização do trabalho possibilitada e, em certa medida, incorporada pelas tecnologias de informação e comunicação suscita dinâmicas nas redes cujas consequências podem ser apreendidas em uma dimensão política da atividade produtiva. É nessa perspectiva que Tiziana Terranova (2000) discute o contexto do trabalho livre, argumentando sobre a necessidade de um esforço analítico que possibilite ir além da noção de que o ciberespaço é um escape da realidade, para compreender como a realidade da internet está profundamente ligada ao

\footnotetext{
${ }^{5}$ Os trechos citados, bem como as informações a que referem, foram retirados da página da plataforma Mineo. Disponível em <http://www.mineo.co/>. Acesso em 15 de abril de 2014.
} 
desenvolvimento das tardias sociedades pós-industriais como um todo. O trabalho a partir da internet não constitui automaticamente todo usuário em produtor ativo e os trabalhadores em sujeitos criativos. "O processo pelo qual a produção e o consumo são reconfigurados dentro da categoria de trabalho livre sinaliza o desdobramento de uma lógica diferente do valor (ao invés de uma completamente nova), cujas operações necessitam uma análise cuidadosa" [tradução nossa] (TERRANOVA, 2000, p. 35).

\section{CONCLUSÃO}

Com efeito, as duas iniciativas observadas com maior ênfase nesse trabalho, bem como diversas outras ligadas a co-criação em design, têm pensado a partir de uma noção de participação que amplia possibilidades de criação. Sem dúvida esses espaços tornam mais abrangentes as condições de produção dos produtos que são desenvolvidos a partir das interações com as comunidades. Entretanto, compreendemos ao observar as dinâmicas propostas pelas plataformas que por si só a colaboração não abre os processos de desenvolvimento efetivamente. Muitos deles continuam condicionados por diversos outros fatores limitantes. De maneira comum, apesar de não se apresentarem sob os moldes das antigas relações de trabalho (como o vínculo empregatício ou a remuneração do trabalho assalariado), ambas as plataformas colocam novos modelos de trabalho ligados às formas de produção contemporâneas, marcadas pela flexibilização e pela não separação entre as esferas da produção e da reprodução social. Nos momentos supostamente livres, os usuários destes modelos persistem numa atividade produtiva, que apesar de prazerosa, continua inscrita sob os valores do trabalho, como possíveis remunerações, recompensas e a produção da própria reputação dentro da rede. Além de condições específicas do trabalho criativo, como a demanda por contribuição constante com ideias, opiniões e relações entre os envolvidos nos processo de criação coletiva. Não se trata aqui de determinar bons ou maus processos nas relações entre produção em design, trabalho colaborativo e as plataformas que têm possibilitado experiências nessas interfaces. As questões sobre a produção de valor a partir da cooperação social no campo do design não podem ser encaradas, tão pouco resolvidas, sem reconhecer o conflito fundamental que colocam: entre a ampliação da participação nos processos criativos e as novas formas de exploração dos produtos e relações advindos desses processos. Queremos aprofundar as questões sobre a forma de se trabalhar com criatividade por entender que elas não se resolvem com sua simples positivação, tão pouco com a crítica radical dessas práticas. Sinalizamos que as conclusões até aqui pontuadas se encontram em estágio preliminar e pretendemos que continuem abertas a novas considerações. É preciso encarar os atravessamentos, os micromovimentos, as táticas dos sujeitos nesses processos, diversos a cada nova análise. Sem deixar de perceber as liberdades, mas também as sujeições de tipo novo que as transformações na produção contemporânea colocam, uma vez que esses novos tipos de trabalho ainda carecem de novas formas de organização e mobilização. Ten Have, presidente da Ponoko, afirma que seu modelo de negócio está envolvido na reformulação do modelo de funcionamento da fábrica para este século. "Estamos criando uma fábrica para o século $21^{\prime \prime}$. A questão que

\footnotetext{
6 "A caminho da fábrica do futuro". Revista Pequenas Empresas, Grandes Negócios. Edição 254 Março/2010. Disponível em <http://revistapegn.globo.com/Revista/Common/0,EMI125212-17171,00A+CAMINHO+DA+FABRICA+DO+FUTURO.html> Acesso em 30 de abril de 2014.
} 
pretendemos abrir aqui trata das práticas e desdobramentos pelos quais os operários cognitivos dessas fábricas digitais serão responsáveis.

\section{REFERÊNCIAS}

ANTOUN, Henrique. De uma teia à outra: a explosão do comum e o surgimento da vigilância participativa. In: ANTOUN, H. (Org.) Web 2.0: participação e vigilância na era da comunicação distribuída. Rio de Janeiro: Mauad X, 2008.

ARMSTRONG, Helen; STOJMIROVIC, Zvezdana. Participate. Designing with usergenerated content. New York: Princeton Architectural Press, 2011.

ANDERSON, Chris. Makers. A Nova Revolução Industrial. Tradução de Afonso Celso da Cunha Serra. Rio de Janeiro: Elsevier, 2012.

DELEUZE, Gilles. Conversações. Tradução Peter Pál Pelbart. São Paulo: Ed. 34, 2010.

GORZ, André. O imaterial. Conhecimento, valor e capital. Tradução de Celso Azzan Júnior. São Paulo: Annablume, 2005.

HESMONDHALGH, David. User-generated content, free labour and the cultural industries. Ephemera, Theory \& Politics in Organization. v. 10, n. 3/4 Warwick Business School, p. 267-284, 2010.

NEGRI, Antônio; LAZZARATO, Mauricio. Trabalho imaterial: Formas de vida e produção de subjetividade. Rio de Janeiro: Lamparina, 2013.

PASSOS, Eduardo; KASTRUP, Virgínia; DA ESCÓSSIA, Liliana. (Org.) Pistas do método da cartografia: Pesquisa-intervenção e produção de subjetividade. Porto Alegre: Sulina, 2009.

SZANIECKI, Barbara. A multidão e o comum da comunicação. Cordel dos Sem. Revista Eco-Pós (Online), v. 15, p. 4-15, 2012.

TERRANOVA, Tiziana. Free Labor: Producing Culture for the Digital Economy. Social Text 63, v 18, n. 2, Duke University Press, p. 33-57, 2000. 